\title{
An audio/video surveillance system for wildlife
}

\author{
Roman Gula • Jörn Theuerkauf • Sophie Rouys • \\ Andrew Legault
}

Received: 27 December 2009/Revised: 5 April 2010 / Accepted: 19 April 2010 / Published online: 13 May 2010

(C) Springer-Verlag 2010

\begin{abstract}
We report 7 years of experience with an inexpensive and reliable continuous audio/video recording system. The main components of the system are commercial, infrared illuminator surveillance cameras, mini microphones and portable digital video recorders, powered by deep cycle leadacid batteries. We used the system for monitoring 41 broods of four endemic bird species in tropical rainforests of New Caledonia. We recorded for over 22,000 $\mathrm{h}$ in total. We kept the system at nests for a maximum period of 7 months, and the longest time we continuously recorded for was 58 days. We watched the recordings at 24-36 times speed and were able to recognise individuals, quantify their behaviour and
\end{abstract}

Communicated by C. Gortázar

R. Gula $(\bowtie) \cdot$ J. Theuerkauf $\cdot$ A. Legault

Museum and Institute of Zoology, Polish Academy of Sciences,

Wilcza 64, 00-679,

Warsaw, Poland

e-mail: rgula@miiz.waw.pl

J. Theuerkauf

e-mail: jtheuer@miiz.waw.pl

A. Legault

e-mail: alegault@utas.edu.au

S. Rouys

Conservation Research New Caledonia,

BP 2549, 98846 Nouméa Cedex, New Caledonia

e-mail: sophierouys@lagoon.nc

\section{A. Legault}

School of Zoology, University of Tasmania,

Private Bag 5,

Hobart, Tasmania 7001, Australia

Present Address:

S. Rouys

Société Calédonienne d'Ornithologie,

BP 3135, 98846 Nouméa Cedex, New Caledonia document visits of predators. The system proved its applicability in behavioural studies of nesting birds, but we believe it is appropriate for continuous monitoring of any site frequently visited by wildlife.

Keywords Methods · Video surveillance .

Nest monitoring $\cdot$ Digital video

\section{Introduction}

Improvements in digital technology over the last decade have facilitated the use of video for studying wildlife. Camera systems featuring motion sensors, time lapse and continuous recording have been widely used to document the presence and behaviour of animals at nests, trap sites and wildlife passages (Reif and Tornberg 2006; Kleist et al. 2007; Huckschlag 2008; Scheibe et al. 2008). Several systems have been developed and tested for continuous monitoring of bird nests (Currie et al. 1996; Dearborn 1996; Delaney and Grubb 1998; Margalida et al. 2006; Lin et al. 2007; Pierce and Pobprasert 2007; Colombelli-Négrel et al. 2009).

The impact of introduced wildlife on native birds is presumed in many cases, but rarely documented and quantified (Towns et al. 2006). Accordingly, rats have been assumed to prey on broods of endemic birds in New Caledonia (Warner 1948; Létocart and Salas 1997; BirdLife International 2009a, b). Our goal was to develop a video surveillance system that allowed continuous monitoring of bird nests in order to: (1) identify nest predators, (2) quantify predation and (3) study the behaviour of nesting birds. In this paper, we present 7 years of experience with an audio/video recording system that we developed and used to monitor broods of four endemic bird species of New Caledonia. 


\section{Study area and methods}

The study areas were located in rainforests of Parc Provincial de la Rivière Bleue $\left(22^{\circ} 3-12^{\prime} \mathrm{S}, 166^{\circ} 33-46^{\prime} \mathrm{E}\right)$ and Parc des Grandes Fougères $\left(21^{\circ} 37-38^{\prime} \mathrm{S}, 165^{\circ} 45-46^{\prime}\right.$ E) in New Caledonia (southwest Pacific). The climate is tropical oceanic, with mean annual temperatures ranging from $22^{\circ} \mathrm{C}$ to $24^{\circ} \mathrm{C}$ (ORSTOM 1981). Annual mean rainfall is 2,500-3,500 $\mathrm{mm}$ (Parc Provincial de la Rivière Bleue) and 1,500-2,000 mm (Parc des Grandes Fougères). Black Rats (Rattus rattus), Pacific Rats (Rattus exulans) and Feral Cats (Felis catus) inhabit both study areas (Rouys and Theuerkauf 2003), and are considered as potential predators of the studied bird species.

The video monitoring system consisted of a commercial infrared illuminator surveillance camera (Sony 1/3" CCD image sensor), and an Electret mini microphone with builtin SMD amplifier (Henri Electronic, Germany), connected to a recording device via a 6.4-mm multicore cable (Fig. 1). The transmission cable consisted of a 3-mm coaxial cable for the video signal, a 2.2-mm coaxial cable for the audio signal and two $2-\mathrm{mm}\left(0.75 \mathrm{~mm}^{2}\right)$ cables to power the camera and microphone. From 2002 to 2007, we used video cassette recorders (Panasonic NV-HV55 VCRs) with standard 4-h VHS tapes set to record for $12 \mathrm{~h}$ on extended play. We powered the systems with $25-\mathrm{kg}$ deep cycle, leadacid batteries with a storage capacity of 100 Ah. In 2007, we replaced VCRs with portable DVRs (Digital Video Recorders), as described by Pierce and Pobprasert (2007). Since then, we have used both Archos ${ }^{\mathrm{TM}} 504$ DVRs (with 80 GB hard drives) and Archos 700 DVRs (with 100 GB hard drives).

All cameras were equipped with 12 infrared light emitting diodes (LEDs) for night vision. Surveillance cameras were waterproof to $1 \mathrm{~m}$, and dust tight (International Protection Rating IP=67), therefore they did not require any additional cover. We put the microphone into a plastic bag, and taped it under the camera body. Initially, we connected the camera and microphone to the transmission cable using commercial video and audio connectors. The system was easy to set up, however connections tended to fail when left at the nest for long periods. Consequently, we dismantled the connectors, soldered the wires from the camera and microphone directly to the transmission cable and sealed the soldered connections with $3 \mathrm{M}^{\mathrm{TM}}$ Temflex ${ }^{\mathrm{TM}}$ Rubber Splicing Tape. We connected the transmission cable to the recorder using a dedicated
Fig. 1 The components and wiring of the audio/video surveillance system

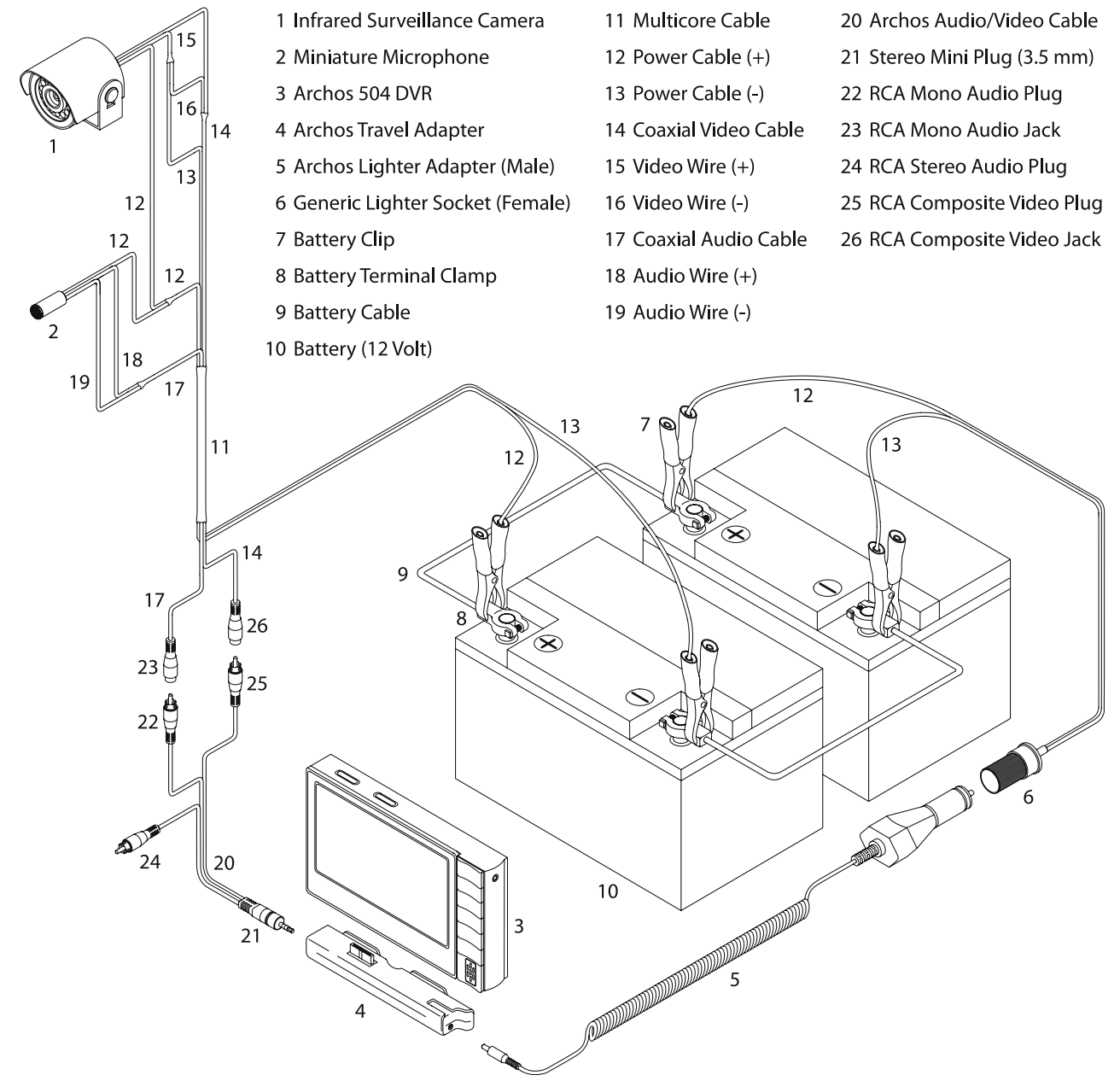


Archos A/V cable. Although we initially used the RCA connectors supplied with the Archos A/V cable (as shown in Fig. 1), we eventually removed them and soldered the mono audio and video wires directly to the transmission cable to prevent connection failures. Our microphone recorded in mono, so we also removed the second RCA plug, and covered any exposed wiring with splicing tape. In other environments, it may be possible to use this cable without modification. This would allow the researcher to use the Archos A/V cable to playback audio on a stereo system, or video on an external monitor or TV. We soldered the transmission cable to the power cables, which led to clips connected to the battery. The VCRs were powered from the battery through a $12 / 220 \mathrm{~V}$ transformer. The DVRs were powered through an Archos car lighter adapter connected to a female lighter socket with power cables clipped to the battery (Fig. 1).

To monitor ground nests, we attached the camera to a 1-m fibreglass stick driven into the soil. For nests in tree hollows, we attached the camera to the tree trunk. When we mounted the camera $20-150 \mathrm{~cm}$ from the bottom of the nest, we used a camera with a $3.6 \mathrm{~mm}$ lens, and when we mounted the camera 100-300 cm from the nest bottom, we used a camera with a $6.0 \mathrm{~mm}$ lens. Due to the length of the transmission cable, we positioned the recorders within $50 \mathrm{~m}$ of the nests. However, this type of cable is technically specified to transmit sound and video up to about $80 \mathrm{~m}$, without requiring additional amplification. We attached the cable to branches at a height of approximately $1 \mathrm{~m}$, in order to minimise damage from rats. We put each recorder in a plastic storage box (dimensions: $40 \times 60 \times 20 \mathrm{~cm}$ for VCRs, $20 \times 30 \times 10 \mathrm{~cm}$ for DVRs), and placed the box on top of the batteries, which remained on the ground. We drilled a $2-\mathrm{cm}$ hole in the bottom of each box to pass the cables through, which also provided ventilation. We used a waterproof tarp to cover the batteries and the box that contained the recorder.

We watched video cassettes at 36 times speed on a TV, and digital video recordings at 24 times speed on a computer. Whenever we noticed an event that we were interested in (arrival of predators, entrance or departure of parents, provision of food, tending of young, nest preparation and social interactions), we rewound the video, watched the event at normal speed and recorded its starting time and duration.

\section{Results}

Between 2002 and 2009, we used seven audio/video surveillance systems for monitoring the nests of four endemic species in New Caledonia: Kagu Rhynochetos jubatus, New Caledonian Parakeet Cyanoramphus saisseti, Horned Parakeet Eunymphicus cornutus and New Caledonian Whistler Pachycephala caledonica (Table 1). In total, we recorded nesting birds for over 22,000 h, and the longest period that we recorded continuously was 58 days. The maximum length of time that we kept a camera at a nest was 7 months (including time before and after breeding). Over this period, we checked weekly if birds were coming to the nest. After the female laid the first egg, we recorded the nest for another 100 days, with the only interruptions being due to poor connections or battery failures.

While watching the recordings of Kagu broods, we were able to recognise individual Kagus that we had marked with metal and colour bands, which made it possible to quantify the different behaviours of nesting Kagus. Also, we could usually identify the type of food that adult Kagus fed their chicks (i.e., earthworms and insects). Although we observed rats visiting the nests, we never recorded any predation (Table 1).

At nests of New Caledonian Parakeets and Horned Parakeets, we used video and sound recordings to differentiate between the behaviour of females, males and chicks (Table 1). In some cases we could recognise individual parakeets, which led to the discovery that two male New Caledonian Parakeets were attending the same nest, and feeding the chicks. Male parakeets often stayed outside the nest, rather than entering it, yet on many occasions we were

Table 1 Tally of various events recorded during video monitoring of endemic birds species in New Caledonia, from 2002 to 2009

\begin{tabular}{lcccc}
\hline Event & $\begin{array}{l}\text { Kagu (7,637 h, } \\
24 \text { broods })\end{array}$ & $\begin{array}{l}\text { New Caledonian Parakeet } \\
(9,606 \mathrm{~h}, 12 \text { broods })\end{array}$ & $\begin{array}{l}\text { Horned Parakeet } \\
(4,761 \mathrm{~h}, 4 \text { broods })\end{array}$ & $\begin{array}{l}\text { New Caledonian Whistler } \\
(293 \mathrm{~h}, 1 \mathrm{brood})\end{array}$ \\
\hline Rat visits & 72 & 16 & 8 & 0 \\
Predation & 0 & 0 & $1^{\mathrm{b}}$ & $1^{\mathrm{c}}$ \\
Feeding of chicks & 1,116 & 2,273 & 287 & 403 \\
Visits by other individuals of the & 44 & $497^{\mathrm{a}}$ & 0 & 0 \\
$\quad$ same family (excluding parents) & & & \\
\hline
\end{tabular}

\footnotetext{
${ }^{a}$ Visits of second male, genetically proved to be second father (Theuerkauf et al. 2009b)

${ }^{\mathrm{b}}$ Predation by introduced Black Rat

${ }^{\mathrm{c}}$ Predation by endemic New Caledonian Friarbird (Philemon diemenensis)
} 
still able to detect their presence by their recorded vocalisations. We also observed visits of potential nest predators, like rats and lizards, and their interactions with nesting females, but only recorded predation once (Table 1).

Our original recording system, equipped with a VCR, required us to change tapes every $12 \mathrm{~h}$, and to change the battery every $36 \mathrm{~h}$. In practice, we were able to record for a maximum of 4.5 days, during which the system consumed the energy of three 100-Ah batteries. The use of DVRs extended the video and audio storage capabilities from $12 \mathrm{~h}$ to 12 days (using a $100 \mathrm{~GB}$ Archos 700), and lowered the power consumption of the system by a factor of four. One new 100-Ah battery was enough to power the system for 6 days. With two 100-Ah batteries, we could record continuous video and sound without intervention for 9 days using an $80 \mathrm{~GB}$ Archos 504, or for 12 days using a $100 \mathrm{~GB}$ Archos 700. After this time, it was necessary to replace the batteries and DVR units. Changing DVR units was more convenient than downloading the recordings because data transfer from the unit to the computer was too time consuming to be carried out in the field.

The cost of one complete system was about 520 euro, including a camera (100 euro), $50 \mathrm{~m}$ cable (50 euro), DVR unit (200 euro), microphone (20 euro) and battery (150 euro). For continuous monitoring, a complete system is required for each nest, plus one extra DVR unit and one extra battery. These needed to be changed every 6 days, and cost an additional 350 euro. We monitored up to three nests at the same time, and found that one extra DVR (a total of four) and two extra batteries (a total of five) were sufficient for this.

\section{Discussion}

The video monitoring system we have described is relatively inexpensive, and easy to assemble. The main components of the system are widely used in commercial surveillance systems. Cameras are available with various focal lengths and different numbers of LEDs (12 or 24), so the type of camera can be altered according to the size of, and distance to, the animal being monitored.

The DVRs we used are popular consumer electronic products with similar functionality to Apple iPods, apart from the ability to record video signals from external cameras. New models of Archos recorders are equipped with up to 320 GB hard drives, which could potentially record 36 days of video and sound. If powered by six 100-Ah batteries, such a system could be left for 36 days without intervention, which would greatly reduce maintenance efforts.

A major advantage of this system is that entire broods can be recorded over a long time period, without interruption. Without the ability to continuously monitor videos, visits of predators and incidents of predation might be easily missed due to their low frequency. The system also proved useful for studying the behaviour of nesting birds, particularly their interactions. We were able to quantify social interactions in Kagus (Theuerkauf et al. 2009a) and discovered polyandry in New Caledonian Parakeets (Theuerkauf et al. 2009b).

We believe that this system is not only applicable to nesting birds, but to any field situation where long-term continuous audio/video recording is required, such as at den sites, prey sites, drinking/feeding sites and animal highway passages. Because the system gathers large amounts of data with relatively little effort, it expands the potential for detailed behavioural studies of animals in the wild, especially the quantification of animal time budgets, interactions and species assemblages at gathering points.

Acknowledgements This study was part of the research project "Impact of introduced mammals and habitat loss on endemic birds of New Caledonia", done in cooperation with the Direction de l'Environnement (Province Sud, New Caledonia), which issued all permits for this study, and financed by the Loro Parque Fundación (Spain), Polish Ministry of Science and Higher Education (Grant 2P04F 001 29), Conservation des Espèces et Populations Animales (France), La Fondation Nature et Découvertes (France), Fonds für bedrohte Papageien-Zoologische Gesellschaft für Arten-und Populationsschutz (Germany), and doctoral grants from Province Sud (to SR) and the University of Tasmania (to AL). We thank M. Broersen, C. Chatreau, P. de Pous, D. Dingemans, S. Duijns, B. Michielsen, E. Minnema, L. Nijdam, H. Theuerkauf, J. van Dijk, M. van Opijnen and J. Wardenaar for their help during field work.

\section{References}

BirdLife International (2009a) Species factsheet: Cyanoramphus saisetti. Downloaded from http://www.birdlife.org on 15/3/2010

BirdLife International (2009b) Species factsheet: Eunymphicus cornutus. Downloaded from http://www.birdlife.org on 15/3/2010

Colombelli-Négrel D, Robertson J, Kleindorfer S (2009) A new audio-visual technique for effectively monitoring nest predation and the behaviour of nesting birds. Emu 109:83-88

Currie D, Nour N, Adriaensen F (1996) A new technique for filming prey delivered to nestlings, making minimal alterations to the nest box. Bird Study 43:380-382

Dearborn DC (1996) Video documentation of a brown-headed cowbird nestling ejecting an indigo bunting nestling from the nest. Condor 98:645-649

Delaney DK, Grubb TG (1998) An infrared video camera system for monitoring diurnal and nocturnal raptors. J Raptor Res 32:290-296

Huckschlag D (2008) Development of a digital infrared video camera system for recording and remote capturing. Eur J Wildl Res 54:651-655

Kleist AM, Lancia RA, Doerr PD (2007) Using video surveillance to estimate wildlife use of a highway underpass. J Wildl Manage 71:2792-2800

Létocart Y, Salas M (1997) Spatial organization and breeding of Kagu Rhynochetos jubatus in Rivière Bleue Park, New Caledonia. Emu 97:97-107

Lin R-S, Yao C-T, Lee P-F (2007) The diet of fairy pitta Pitta nympha nestlings in Taiwan as revealed by videotaping. Zool Stud 46:355-361 
Margalida A, Ecolan S, Boudet J, Bertran J, Martinez J-M, Heredia R (2006) A solar-powered transmitting video camera for monitoring cliff-nesting raptors. J Field Ornithol 77:7-12

ORSTOM (1981) Atlas de la Nouvelle-Calédonie et Dépendances. Éditions de l'Office de la Recherche Scientifique et Technique Outre Mer, Paris

Pierce AJ, Pobprasert K (2007) A portable system for continuous monitoring of bird nests using digital video recorders. Field Ornithol 78:322-328

Reif V, Tornberg R (2006) Using time-lapse digital recording for a nesting study of birds of prey. Eur J Wildl Res 52:251-258

Rouys S, Theuerkauf J (2003) Factors determining the distribution of introduced mammals in nature reserves of the southern province, New Caledonia. Wildl Res 30:187-191
Scheibe KM, Eichhorn K, Wiesmayr M, Schonert B, Krone O (2008) Long-term automatic video recording as a tool for analysing the time patterns of utilisation of predefined location by wild animals. Eur J Wildl Res 54:53-59

Theuerkauf J, Rouys S, Mériot JM, Gula R (2009a) Group territoriality as a form of cooperative breeding in the flightless Kagu of New Caledonia. Auk 126:371-375

Theuerkauf J, Rouys S, Mériot JM, Gula R, Kuehn R (2009b) Cooperative breeding, mate guarding, and nest sharing in two parrot species of New Caledonia. J Ornithol 150:791-797

Towns DR, Atkinson IAE, Daugherty CH (2006) Have the harmful effects of introduced rats on islands been exaggerated? Biol Inv 8:863-891

Warner DW (1948) The present status of kagu, Rhynochetos jubatus, on New Caledonia. Auk 65:287-288 